\title{
The role of exogenous humic and fulvic acids in iodine biofortification in spinach (Spinacia oleracea L.)
}

\author{
Sylwester Smoleń • Iwona Ledwożyw-Smoleń • \\ Włodzimierz Sady
}

Received: 3 July 2015 / Accepted: 21 December 2015 / Published online: 28 December 2015

(C) The Author(s) 2015. This article is published with open access at Springerlink.com

\begin{abstract}
Background and aims The strong sorption of iodine in soils is a major factor that limits its uptake by plants. The aim of this study was to evaluate the influence of Humistar (a concentrate of exogenous humic acids $12 \% \mathrm{w} / \mathrm{w}$ and fulvic acids $3 \% \mathrm{w} / \mathrm{w}$; abbreviated: HU) applied with $\mathrm{KI}$ or $\mathrm{KIO}_{3}$ on the efficiency of iodine biofortification, yield and the accumulation of undesirable compounds in spinach.

Methods Methods of iodine application with or without HU were tested in two pot experiments and a hydroponic study with spinach cultivation. The spinach biomass and the content of iodine, soluble oxalates, $\mathrm{Cd}$ and $\mathrm{Pb}$ in leaves were determined. The physicochemical properties and chemical composition of the soil and media were analysed.
\end{abstract}

Responsible Editor: Philip John White.

Electronic supplementary material The online version of this article (doi:10.1007/s11104-015-2785-x) contains supplementary material, which is available to authorized users.

S. Smoleń $(\bowtie) \cdot$ W. Sady

Unit of Plant Nutrition, Institute of Plant Biology and

Biotechnology, Faculty of Biotechnology and Horticulture,

University of Agriculture in Kraków, Al. 29 Listopada 54,

31-425 Kraków, Poland

e-mail: s.smolen@ogr.ur.krakow.pl

I. Ledwożyw-Smoleń

Unit of Biochemistry, Institute of Plant Biology and

Biotechnology, Faculty of Biotechnology and Horticulture,

University of Agriculture in Kraków, Al. 29 Listopada 54,

31-425 Kraków, Poland
Results No negative influence of iodine and HU on spinach yield was observed. Fertigation with iodine resulted in a higher efficiency of iodine biofortification than its application pre-sowing (particularly for $\mathrm{KIO}_{3}$ ), with no increase in the $\mathrm{Cd}$ and $\mathrm{Pb}$ content in spinach plants compared to the control.

Conclusion The improvement of iodine uptake and root-to-leaf transfer (represented by higher transfer factor values) in spinach can be obtained by the application of $\mathrm{HU}$ via plant fertigation with $\mathrm{IO}_{3}{ }^{-}$. The level of soluble oxalates in spinach grown in the pot experiments was not affected.

Keywords Biofortification · Iodine · Spinach $\cdot$ Humic acids $\cdot$ Fulvic acids $\cdot$ Cadmium $\cdot$ Lead

\section{Abbreviations \\ HU Humistar (commercial concentrate of humic and fulvic acids) \\ NFT Nutrient Film Technique \\ IDD Iodine Deficiency Disorders \\ Fertig. Fertigation \\ RDA Recommended Daily Allowance \\ SOM Soil Organic Matter}

\section{Introduction}

Iodine is a micronutrient that is essential for the proper functioning of human and animal organisms, in the prenatal period as well as during the initial years of life 
(Walker et al. 2007; Charlton et al. 2010; MelseBoonstra and Jaiswal 2010; Guyot et al. 2011). Despite the extensive programme of salt iodisation, approximately 30 to $38 \%$ of the entire human population suffers from inadequate iodine intake. Iodine deficiency disorder (IDD) is a term that describes the entire spectrum of dysfunctions related to the inadequate supply of this micronutrient in the diet (Delange 1998; White and Broadley 2009; Winger et al. 2008).

The iodine biofortification of plants is proposed as an alternative way to introduce iodine into food and can be an efficient method of IDD prevention. Iodine is not an essential nutrient for plants, therefore, prior to the implementation of biofortification rules into agricultural practice, optimal agrotechnical methods for its application need to be developed.

In the soil environment, iodine undergoes strong sorption with soil organic matter or mineral fractions. This process occurs from $2 \mathrm{~h}$ (Hakimi 1996) to a few days (Muramatsu et al. 1990; Kashparov et al. 2005) after iodine introduction into the soil. Basically, iodine can be bound only to decomposed, humified organic matter, but not to fresh organic matter (Muramatsu et al. 1996).

It has been reported that iodine readily interacts with aromatic compounds (phenolics and polyphenols) that have double bonds (Johanson 2000; Schlegel et al. 2006). Because the structure of fulvic acids and humins includes aromatic rings, endogenous components of soil organic matter covalently bind iodine, resulting in its strong sorption by soil (Muramatsu et al. 1996; Johanson 2000; Schlegel et al. 2006). The process of iodine sorption to mineral fractions of soil: Fe/Al hydroxide (Muramatsu et al. 1990; Yoshida et al. 1992) $\mathrm{Cu} / \mathrm{Al}$ and $\mathrm{Cu} / \mathrm{Cr}$ hydroxide, (Pless et al. 2007) as well as various forms of $\mathrm{Cu}(\mathrm{I})$-sulphides and $\mathrm{Cu}(\mathrm{I})-\mathrm{Fe}(\mathrm{III})-$ sulphides (Lefèvre et al. 2003) has also been reported. Iodine desorption in the soil environment, on the other hand, is very slow (Dai et al 2004). As a consequence, the above-mentioned sorption processes contribute to a strong limitation of iodine transfer in the soil-plant system.

In addition to a detailed description of the processes leading to iodine loss from the soil due to its volatilisation in the form of $\mathrm{I}_{2}$ or $\mathrm{CH}_{3} \mathrm{I}$, the conversion of speciation forms of iodine in the soil environment also depends on mutual and complex relations between the values of $\mathrm{pH}$ and redox potential (Eh). These can lead to transformations between $\mathrm{I}^{-}$and $\mathrm{IO}_{3}{ }^{-}$or the production of $\mathrm{I}_{2}$ (Vinogradov and Lapp 1977; Fuge and Johnson 1986; Johnson 2003; Fuge 2013). Importantly, under aerobic conditions (in upland fields), humic acids are involved in the reduction of iodate $\left(\mathrm{IO}_{3}{ }^{-}\right)$to molecular iodine, which can further volatilise or interact with soil organic matter (SOM) to create organo-iodine compounds (Yamaguchi et al. 2005, 2006).

Concentrates of exogenous humic and fulvic acids can be considered to be substitutes of organic fertilization. One of the effects of their application might be their limited solubility (bioavailability in the soil) and absorption of heavy metals by roots (Tyler and McBride 1982).

Studies conducted to date on the iodine biofortification of plants have not included the problem of the interaction between such concentrates and iodine compounds applied to soil in the form of iodides and iodates. The recognition of this issue is important, due to the above-mentioned influence of humic acids on iodine sorption and/or transformation in the soil environment.

The aim of the study was to evaluate the influence of Humistar (a concentrate of exogenous humic and fulvic acids), as well as the different chemical forms and methods of iodine application on the effectiveness of iodine biofortification, yield and the accumulation of $\mathrm{Cd}, \mathrm{Pb}$ and soluble oxalates in spinach.

\section{Materials and methods}

The studies were conducted on spinach (Spinacia oleracea L.) cv. 'Olbrzym zimowy' grown in pots or hydroponics, including the application of iodine and a concentrate of humic and fulvic acids. Iodine was applied in the form of pure compounds: KI (P.O.Ch., Poland) and $\mathrm{KIO}_{3}$ (Sigma-Aldrich, Germany). The source of humic and fulvic acids was a commercial concentrate - Humistar (abbreviated as HU), produced by TRADECORP, Spain. Humistar is a liquid soil amendment based on American Leonardite (a natural form of humates) from North Dakota (USA) mines that contains $12 \% \mathrm{w} / \mathrm{w}$ humic acids and $3 \% \mathrm{w} / \mathrm{w}$ fulvic acids.

Plant culture and pot experiments

In the spring season of 2009 and 2010, two independent pot experiments (experiments no. 1 and 2) with spinach cultivation were conducted. The plants 
were cultivated in open $60 \times 40 \times 20 \mathrm{~cm}$ containers, placed in a plastic tunnel. The containers were filled with $45 \mathrm{dm}^{3}$ of silt and loam soil with the following granulometric composition: 35 sand, $28 \%$ silt and $37 \%$ clay (according to the ISSS classification). The soil characteristics, before the initiation of the experiment (prior to the application of fertilizers, HU and the sowing of seeds) were as follows: the $\mathrm{pH}_{(\mathrm{H} 2 \mathrm{O})}$ was 6.97 , Eh $+326.7 \mathrm{mV}$, the electrical conductivity (EC, total salinity) was $0.31 \mathrm{mS} \cdot \mathrm{cm}^{-1}$ and the mean organic matter content was $2.76 \%$. The content of the available forms of mineral nutrients and iodine was determined (after extraction with $0.03 \mathrm{M}$ acetic acid) and was: $\mathrm{N}\left(\mathrm{N}_{-} \mathrm{NO}_{3}+\mathrm{N}-\right.$ $\left.\mathrm{NH}_{4}\right) 58.7 \mathrm{mg}, \mathrm{P} 39.3 \mathrm{mg}, \mathrm{K} 73.3 \mathrm{mg}, \mathrm{Mg}$ $151.5 \mathrm{mg}$, Ca $1,245.2 \mathrm{mg}, \mathrm{S} 17.2 \mathrm{mg}$, Na $6.8 \mathrm{mg}$, $\mathrm{Cl} 0.0, \mathrm{Fe} 0.47 \mathrm{mg}, \mathrm{Al} 3.6 \mathrm{mg}, \mathrm{Cu} 71.2 \mu \mathrm{g}, \mathrm{Cr}$ $11.3 \mu \mathrm{g}$ and iodine $2.6 \mathrm{mg}$ in $1 \mathrm{dm}^{3}$ of soil. Based on these data, soil fertilization with nitrogen, phosphorus and potassium was performed to the levels of: $100 \mathrm{mg} \mathrm{N}, 60 \mathrm{mg} \mathrm{P}$ and $160 \mathrm{mg} \mathrm{K} \mathrm{dm}^{-3}$ soil, using $\mathrm{Ca}\left(\mathrm{NO}_{3}\right)_{2}, \mathrm{KH}_{2} \mathrm{PO}_{4}$ and $\mathrm{K}_{2} \mathrm{SO}_{4}$. After soil extraction with $1 \mathrm{M} \mathrm{HCl}$, the following concentrations were determined: $\mathrm{Fe}$ 1,291.5 mg, Al, $1,176.8 \mathrm{mg}, \mathrm{Cu}, 4.75 \mathrm{mg}$ and $\mathrm{Cr} 1.01 \mathrm{mg} \mathrm{kg}^{-1}$ soil. In both research years, the same soil batch was used, which was obtained from a field at an experimental station of the University of Agriculture in Kraków $\left(50^{\circ} 07^{\prime} 910 \mathrm{~N} ; 1^{\circ} 84^{\prime} 764 \mathrm{E}\right)$ in spring 2009 . The soil used for spinach cultivation in 2010 was stored in a heap, protected from precipitation and sunlight.

The experimental factors tested in the study were: the pre-sowing introduction of iodine and $\mathrm{HU}$, and fertigation with iodine.

Experiment no. 1 included the treatment with HU and $\mathrm{KI}$ in the following combinations: 1 - control (without HU and iodine), 2 - pre-sowing HU application, 3 pre-sowing KI fertilization, 4 - pre-sowing HU application with $\mathrm{KI}$ fertilization $(\mathrm{HU}+\mathrm{KI}), 5$ - fertigation with KI (Fertig. KI), 6 - pre-sowing HU application and fertigation with $\mathrm{KI}(\mathrm{HU}+$ Fertig. KI).

Experiment no. 2 included the application of $\mathrm{HU}$ and $\mathrm{KIO}_{3}$ in the following combinations: 1 - control (without HU and iodine application), 2 - pre-sowing HU application, 3 - pre-sowing $\mathrm{KIO}_{3}$ fertilization, 4 pre-sowing $\mathrm{HU}$ application with $\mathrm{KIO}_{3}$ fertilization $\left(\mathrm{HU}+\mathrm{KIO}_{3}\right), 5$ - fertigation with $\mathrm{KIO}_{3}\left(\right.$ Fertig. $\left.\mathrm{KIO}_{3}\right)$, 6 - pre-sowing $\mathrm{HU}$ application and fertigation with $\mathrm{KIO}_{3}$ (HU+ Fertig. $\mathrm{KIO}_{3}$ ).
In both pot experiments, Humistar was applied at a dose of $0.2 \mathrm{~mL} \cdot \mathrm{dm}^{-3}$ of soil, whereas iodine in both forms $\left(\mathrm{KI}, \mathrm{KIO}_{3}\right)$ was applied at a dose of $1 \mathrm{mg} \mathrm{dm}^{-3}$ soil. With $\mathrm{HU}$ at a dose $0.2 \mathrm{~mL} \cdot \mathrm{dm}^{-3}$ soil approximately $33 \mathrm{mg}$ of organic matter $\mathrm{dm}^{-3}$ soil was introduced (based on a ratio of $1 \mathrm{~kg}$ soil per $20.6 \mathrm{mg}$ organic matter) $-16.0 \mathrm{mg}$ organic-C $\mathrm{dm}^{-3}$ soil or $10.3 \mathrm{mg}$ organic- $\mathrm{C} \mathrm{kg}^{-1}$ soil. During the cultivation, the plants were irrigated with the same amount of tap water (Table 1), except for treatments no. 5 and 6 in both experiments, for which a $0.0004 \% \mathrm{w} / \mathrm{v}$ iodine solution was used for each fertigation. In total, approximately 1.2 and $1.0 \mathrm{mg} \mathrm{I} \cdot \mathrm{dm}^{-3}$ (in 2009 and 2010 , respectively) was introduced into the soil throughout the spinach cultivation (Table 1).

These experiments were carried out independently, using a randomised method, with three replications. Each replicate (one container) consisted of four rows with 10 plants per row, i.e., 40 plants. Seeds were sown on 20 and 23 March in the subsequent years, with 20 seeds per row. After germination, the plants were singled out, to leave 10 seedlings per row. The spinach was harvested on 28 April, 2009 and 4 May, 2010. During the harvest, the spinach yield and the mean plant weight were estimated (including only above-ground parts; leaves with petioles and stems).

Plant culture - hydroponic experiment

A study of the hydroponic system based on the Nutrient Film Technique (NFT) was conducted in autumn 2009 and 2010, to verify the results obtained in the spring pot

Table 1 Amount of water used for plant irrigation as well as iodine introduced to soil with fertigation during spinach cultivation in Experiment 1 and 2

\begin{tabular}{llll}
\hline & $\begin{array}{l}\text { Year } \\
2009\end{array}$ & $\begin{array}{l}\text { Year } \\
2010\end{array}$ & Average \\
\hline $\begin{array}{l}\text { Amount of water used for } \\
\text { plant irrigation per one } \\
\text { container (from seed } \\
\text { sowing to harvest) in } \\
\text { each treatment of both } \\
\text { pot experiments }\end{array}$ & $14 \mathrm{dm}^{3}$ & $12.5 \mathrm{dm}^{3}$ & $13.25 \mathrm{dm}^{3}$ \\
$\begin{array}{l}\text { Total amount of iodine } \\
\text { introduced per 1 dm of } \\
\text { soil in combination with } \\
\text { KI and } \mathrm{KIO}_{3} \text { in both pot } \\
\text { experiments }\end{array}$ & $1.2 \mathrm{mg} \mathrm{I}^{-3}$ & $1.0 \mathrm{mg} \mathrm{I}^{-3}$ & $1.10 \mathrm{dmg} \mathrm{I}^{-3}$ \\
\hline
\end{tabular}


experiment No 2. Therefore, the hydroponic experiment was limited only to the application of one iodine form $\left(\mathrm{KIO}_{3}\right)$ to the spinach culture.

The experimental NFT system was located in a plastic tunnel and consisted of four independent replicates, each including a $200-\mathrm{dm}^{3}$ nutrient solution tank, two crop gutters ( $2.5 \mathrm{~m}$ long, $20 \mathrm{~cm}$ wide, $5 \mathrm{~cm}$ deep) and a submersible water pump. The pump for all four sets was monitored by a joint control system. The crop gutters were filled with a $2 \mathrm{~cm}$ layer of substrate [sand and perlite in a 1:1 (v:v) ratio], in which seeds were sown. The frequency of plant watering was adjusted to the growth stage as well as to the air temperature, humidity and insolation. Throughout the cultivation period, a single nutrient solution batch was used, with the following composition: $150 \mathrm{mg} \mathrm{N},\left(60 \mathrm{mg} \mathrm{N}-\mathrm{NH}_{4}\right.$ and $90 \mathrm{mg} \mathrm{N}-\mathrm{NO}_{3}$ ), $50 \mathrm{mg} \mathrm{P}, 200 \mathrm{mg} \mathrm{K}, 40 \mathrm{mg} \mathrm{Mg}$, $120 \mathrm{mg} \mathrm{Ca}, 115 \mathrm{mg} \mathrm{S}$ and $70 \mathrm{mg} \mathrm{Cl}$ per $\mathrm{dm}^{3}$ with a pH 5.50 and EC of $1.90 \mathrm{mS} \cdot \mathrm{cm}^{-1}$. The following mineral fertilizers were used for its preparation: ammonium nitrate (Zakłady Azotowe in Tarnów, Poland), monopotassium phosphate, potassium sulphate, magnesium sulphate and calcium chloride (Yara International ASA). Micronutrients were introduced with a multielement Pionier Mikro fertilizer (Arnaud, former Broste), at a dose of $0.075 \mathrm{~mL} \cdot \mathrm{dm}^{-3}$. The concentration of iodine, cadmium and lead in the nutrient solution was assayed using the ICP-OES technique, and the results

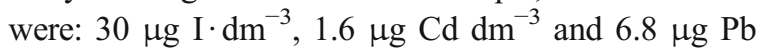
$\mathrm{dm}^{-3}$. In each combination tested, an initial nutrient solution volume of $200 \mathrm{dm}^{3}$ was sufficient for plant growth from seed sowing to harvest.

The study included the addition of $\mathrm{HU}$ and $\mathrm{KIO}_{3}$ to the nutrient solution in the following combinations: 1 control (without $\mathrm{HU}$ and iodine application), 2 - HU, 3 $-\mathrm{KIO}_{3}, 4-\mathrm{KIO}_{3}$ and $\mathrm{HU}$. Both Humistar and $\mathrm{KIO}_{3}$ were introduced at the beginning of cultivation and at seed sowing at a dose of $0.2 \mathrm{~mL} \cdot \mathrm{dm}^{-3}$ and $4 \mathrm{mg}$ $\mathrm{I} \cdot \mathrm{dm}^{-3}$, respectively.

The experiment was carried out in four replicates, each consisting of 50 plants. The seeds were sown on 15 and 6 September in the subsequent years, with 100 seeds sown per replicate. After germination, the plants were singled out, leaving 50 seedlings per replicate. The spinach was harvested on 16 and 8 November in 2009 and 2010, respectively. After the harvest, the yield of aboveground parts (leaves with petioles and stems) and roots was evaluated, followed by the estimation of the weight of a single whole plant.
Plant analysis

Samples of spinach leaves from pot experiments as well as of leaves and roots from hydroponic cultivation were dried at $70{ }^{\circ} \mathrm{C}$ in a laboratory dryer with forced air circulation. Dried samples were ground in a variable speed rotor mill Pulverisette 14, FRITSCH using a $0.5 \mathrm{~mm}$ sieve. The content of $\mathrm{I}, \mathrm{Cd}, \mathrm{Pb}$ and soluble oxalates was then analysed in these ground samples.

The content of iodine, cadmium and lead was determined using a Prodigy ICP-OES spectrometer (Teledyne Leeman Labs USA). The concentration of soluble oxalates was analysed by titration with $0.02 \mathrm{~mol} \mathrm{KMnO}_{4}$, following extraction with boiling distilled water (Wierzbicka 2004).

The iodine concentration in the leaves and roots was determined after incubating the sample with $1 \mathrm{~mL} 25 \%$ TMAH and $10 \mathrm{~mL}$ double-distilled water and $0.5 \mathrm{~g}$ plant material was incubated for $3 \mathrm{~h}$ at $90^{\circ} \mathrm{C}$, in closed Falcon tubes (PN-EN 15111 2008). Additionally, the iodine recovery from fortified samples after incubation with TMAH was determined, and was $89.3 \% \pm 3.7(n=15)$.

The levels of $\mathrm{Cd}$ and $\mathrm{Pb}$ in spinach leaves were analysed after microwave digestion in $65 \%$ super pure $\mathrm{HNO}_{3}$ using a microwave digester (Pasławski and Migaszewski 2006). To evaluate the accuracy of the analysis, the content of these elements in certified peach leaf reference material, (CRM 3 1547), was additionally determined. The obtained results were as follows: 0.03 $\pm 0.003 \mathrm{mg} \mathrm{Cd} \mathrm{kg}{ }^{-1}$ d.w. and $0.81 \pm 0.22 \mathrm{mg} \mathrm{Pb} \mathrm{kg}^{-1}$ d.w. for the certified value of $0.03 \mathrm{mg} \mathrm{Cd} \mathrm{kg}^{-1}$ d.w. and $0.87 \mathrm{mg} \mathrm{Pb} \mathrm{kg}^{-1}$ d.w.

Soil analysis

Prior to plant cultivation in pot experiments, the soil $\mathrm{pH}$, $\mathrm{EC}$, Eh as well as the contents of: organic matter, total $\mathrm{N}$ $\left(\mathrm{N}-\mathrm{NO}_{3}+\mathrm{N}-\mathrm{NH}_{4}\right), \mathrm{P}, \mathrm{K}, \mathrm{Mg}, \mathrm{Ca}, \mathrm{S}, \mathrm{Na}, \mathrm{Cl}, \mathrm{Fe}, \mathrm{Al}, \mathrm{Cu}$, $\mathrm{Cr}$ and iodine were analysed after extraction in $0.03 \mathrm{M}$ acetic acid. After the extraction of soil with $1 \mathrm{M} \mathrm{HCl}$, the concentration of $\mathrm{Fe}, \mathrm{Al}, \mathrm{Cu}$ and $\mathrm{Cr}$ was also determined. The results obtained were used for the characterisation of the soil and are presented in the section "Plant culture - pot experiments". Each of the following parameters was additionally assayed after spinach cultivation: $\mathrm{pH}$, EC, Eh and the content of I, $\mathrm{Cd}$ and $\mathrm{Pb}$ (Table S1).

In soil samples mixed with water $\left(1: 2 \mathrm{v} / 1\right.$, soil: $\left.\mathrm{H}_{2} \mathrm{O}\right)$, $\mathrm{pH}$ and redox potential (Eh) were measured potentiometrically, and the total soil salinity (EC) was measured 
using a conductivity meter. To estimate the content of the available forms of $\mathrm{N}\left(\mathrm{N}-\mathrm{NO}_{3}+\mathrm{N}-\mathrm{NH}_{4}\right), \mathrm{P}, \mathrm{K}, \mathrm{Mg}$, $\mathrm{Ca}, \mathrm{S}, \mathrm{Na}, \mathrm{Cl}$ and iodine, soil extraction with $0.03 \mathrm{M}$ acetic acid was performed (Nowosielski 1988). The concentrations of $\mathrm{Cd}$ and $\mathrm{Pb}$ in soil were analysed following soil extraction with $1 \mathrm{M} \mathrm{HCl}$ (Gorlach et al. 1999). The concentrationsof $\mathrm{N}-\mathrm{NO}_{3}$ and $\mathrm{N}-\mathrm{NH}_{4}$ were measured using the FIA /Flow Injection Analysis technique (PN-EN ISO 13395: 2001, PN-EN ISO 11732:2005 (U)), those of $\mathrm{K}, \mathrm{Mg}, \mathrm{Ca}, \mathrm{S}, \mathrm{Na}, \mathrm{Cl}, \mathrm{I}, \mathrm{Cd}$, $\mathrm{Pb}, \mathrm{Fe}, \mathrm{Al}, \mathrm{Cu}$ and $\mathrm{Cr}$ were estimated using an ICP-OES spectrometer and that of chlorides, using the nephelometric method (Nowosielski 1988).

Meteorological data

During spinach cultivation in pot experiments no. 1 and 2 (in spring 2009 and 2010), the mean daily temperature and relative humidity remained at comparable levels (Figure S1 A). and were $13.7{ }^{\circ} \mathrm{C}$ and $67.4 \%$ in 2009, respectively, and $15.5{ }^{\circ} \mathrm{C}$ and $68.8 \%$ in 2010 , respectively.

A comparable mean daily temperature was observed in autumn 2009 and 2010, i.e., during the spinach cultivation in hydroponics (Figure S1 B). For several days at the beginning and end of spinach cultivation in 2009 , a lower air humidity was observed compared to the corresponding period in 2010 . The mean daily temperature and air humidity throughout the spinach cultivation in a hydroponic system were, $12.5^{\circ} \mathrm{C}$ and $72.4 \%$ in 2009, respectively, and $12.9{ }^{\circ} \mathrm{C}$ and $81.3 \%$ in 2010 , respectively.

\section{Data analysis}

The daily iodine requirement for children above 12 years old and adults (with the exception of pregnant and lactating women) is $150 \mu \mathrm{g}$ I (Andersson et al. 2007). The mean serving of leafy vegetables (including spinach) is approximately $50 \mathrm{~g}$ f.w. (Voogt et al. 2010). Based on this and the results of the iodine content in spinach, the percentage of the Recommended Daily Allowance of iodine (RDA) from one serving of $50 \mathrm{~g}$ f.w. of spinach was calculated, and was used as a target of biofortification.

The results of the iodine determination in the soil,

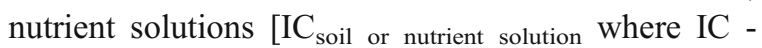
iodine concentration] and in spinach $\left[\mathrm{IC}_{\text {plants }}\right.$ (dry matter) enabled the estimation of the iodine transfer factor
$\left[\mathrm{TF}_{\text {leaf }}\right]$ in the soil/nutrient solution-to-leaf system to be calculated based on the following formula: $\mathrm{TF}_{\text {leaf }}=\left[\mathrm{IC}_{\text {plants (dry matter) }}\right] /\left[\mathrm{IC}_{\text {soil or nutrient solution }}\right]$. For soil, the $\mathrm{IC}_{\text {soil }}$ value was the total content of iodine determined in the soil using the ICP technique and applied by pre-sowing fertilisation or fertigation.

The data were subjected to variance analysis using the ANOVA module of Statistica 10.0 PL. This test was employed to verify whether the tested factors had a significant influence on the spinach field as well as the analysed parameters of the chemical composition of the plants and soil. The Tukey test was used to determine the significance between the means at a significance level of $P<0.05$. The results were calculated separately for each of year of study.

\section{Results}

Spinach biomass

In both pot experiments, no significant influence of $\mathrm{HU}$ and iodine application (as iodides, iodates applied before seed sowing or by fertigation) was observed on the mean weight of the spinach leaves in 2009 and 2010 (Fig. 1a and b). In hydroponic cultivation, no significant effects of $\mathrm{KIO}_{3}+\mathrm{HU}$ application on spinach leaves, roots or whole plants biomass was found in either year of the study (Fig. 2a). In comparison to the control, a significant increase in the weight of leaves, roots and whole plants (roots and leaves) was observed for spinach cultivated with the nutrient solution containing $\mathrm{KIO}_{3}$ or $\mathrm{HU}$ (Fig. 2a-c).

Efficiency of iodine biofortification and iodine transfer factor in spinach

In all three experiments, a significant influence of the tested factors was observed with respect to the iodine content in spinach, as well as the values of TF and RDA (Figs. 3a-f and 4a-e).

In both years of the study, spinach fertigation with KI or $\mathrm{KIO}_{3}$ (individually or combined with $\mathrm{HU}$ ) made it possible to obtain from three to ten orders of magnitude higher accumulation of iodine in the leaves of plants cultivated in both pot experiments compared to the presowing application of these compounds (Fig. 3a and b). Similar relationships were observed for the calculated values of TF and RDA (Fig. 3c-f). Plant fertigation with 


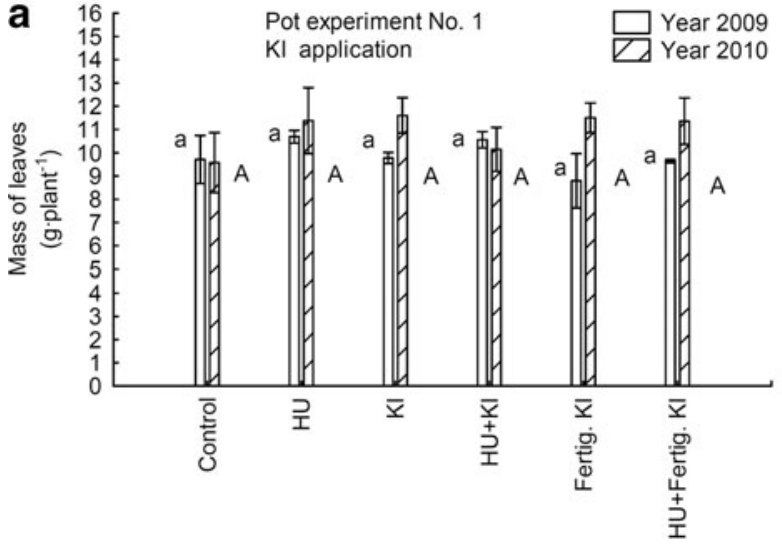

Fig. 1 Fresh mass of leaves of spinach depending of the application of Humistar (HU) and iodine in the form of $\mathrm{KI}(\mathbf{a})$ and $\mathrm{KIO}_{3}$ (b) in pot experiment no. 1 and $2(n=3)$. Means followed by the

$\mathrm{IO}_{3}{ }^{-}$solution (irrespective of $\mathrm{HU}$ addition) increased the efficiency of iodine biofortification of spinach (also TF and RDA values) compared to the application of $\mathrm{I}^{-}$. No significant effect of Humistar application on iodine accumulation, TF and RDA in spinach leaves was observed, whereas for $\mathrm{IO}_{3}{ }^{-}$, an increase in the content of I, TF and RDA in spinach after the pre-sowing application of $\mathrm{HU}+$ fertigation $\mathrm{KIO}_{3}$ was observed, compared to fertigation with $\mathrm{KIO}_{3}$ alone (Fig. 3c). Similar results regarding a greater iodine accumulation and higher values of TF and RDA coefficients in spinach leaves were observed in the hydroponic cultivation for the nutrient solution containing $\mathrm{KIO}_{3}+\mathrm{HU}$, compared to $\mathrm{KIO}_{3}$ alone (Fig. 4a, c and e). Unlike in the pot experiment, the application of $\mathrm{HU}$ to the hydroponic nutrient solution, independently or together with $\mathrm{KIO}_{3}$, significantly decreased the iodine content and TF concentration in roots, compared to the control or treatment with $\mathrm{KIO}_{3}$ alone (Fig. $4 \mathrm{~b}$ and d).

No significant differences were obtained with respect to the efficiency of iodine biofortification, TF and RDA values of spinach after the pre-sowing application of KI, compared to in the HU $+\mathrm{KI}$ treatment (Fig. 3a). Similar results were obtained for the respective combinations with $\mathrm{KIO}_{3}$ and $\mathrm{HU}+\mathrm{KIO}_{3}$ application (Fig. 3b). However, the content of iodine, as well as the values of $\mathrm{TF}$ and RDA for spinach fertilized with $\mathrm{KIO}_{3}$ and $\mathrm{HU}+\mathrm{KIO}_{3}$, did not significantly differ from the control and the soil application of $\mathrm{HU}$ alone. However, the mean iodine content in the spinach after the pre-sowing application of $\mathrm{KIO}_{3}$ and $\mathrm{HU}+\mathrm{KIO}_{3}$ was 9.0 and $10.6 \mathrm{mg}$ $\mathrm{I} \cdot \mathrm{kg}^{-1}$ d.w., respectively, which was 6.7 and $8.3 \mathrm{mg}$

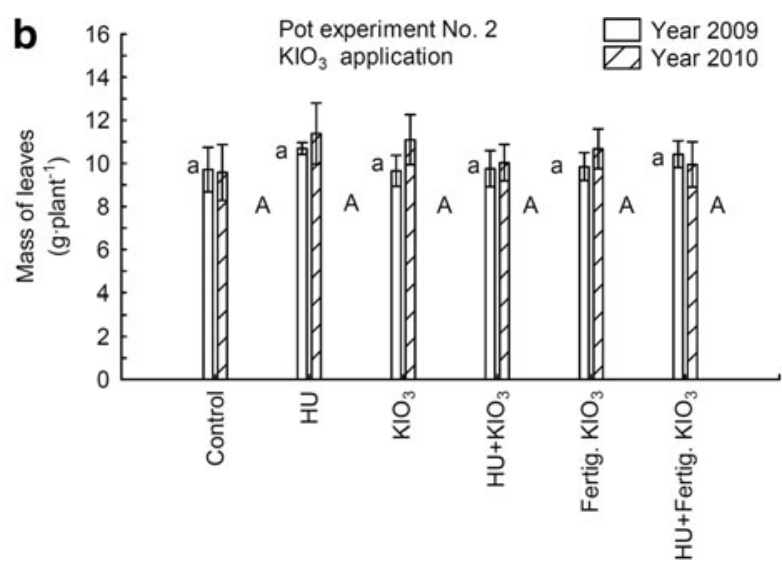

same letters are not significantly different at $P<0.05$ : small letters and capital letters, represent, respectively, the results from 2009 to 2010. Bars indicate the standard error

$\mathrm{I} \cdot \mathrm{kg}^{-1}$ d.w. higher (by 291.3 and $360.8 \%$ ) than in the control plants. The iodine content in the spinach after pre-sowing fertilization with $\mathrm{KI}$ and $\mathrm{HU}+\mathrm{KI}$ (pot experiment no. 1) was, respectively, 6.8 and $6.7 \mathrm{mg} \mathrm{I} \cdot \mathrm{kg}^{-1}$ d.w. i.e., 4.5 and $4.4 \mathrm{mg} \mathrm{I} \cdot \mathrm{kg}^{-1}$ d.w. higher (by 195.6 and $191.3 \%$ ) than in the control.

In each year of the pot experiment, the values of TF and RDA for the spinach in combination treatments with $\mathrm{KIO}_{3}$ fertigation (applied alone or combined with $\mathrm{HU}$ ) were several-fold higher than for KI fertigation (Fig. 3af). In the hydroponic study, the value of iodine TF for spinach leaves, as well as RDA, exceeded those observed in the pot cultivation by one to two orders of magnitude (Fig. 4c and e). Additionally, the values of iodine $\mathrm{TF}$ for spinach roots and leaves collected in the treatments with the addition of $\mathrm{KIO}_{3}$ and $\mathrm{KIO}_{3}+\mathrm{HU}$ to the nutrient solution were substantially lower than those for the control and the combination with HU alone (Fig. 4c and d). In comparison to the control, the application of HU alone caused a significant increase in iodine $\mathrm{TF}$ in the leaves, and a decrease in the roots.

The effect of treatments on the accumulation of $\mathrm{Cd}, \mathrm{Pb}$ and oxalates in spinach

A significant effect of the treatments was observed with respect to the content of $\mathrm{Cd}$ and $\mathrm{Pb}$ in the pot and hydroponic experiments in both 2009 and 2010 . Additionally, the accumulation of soluble oxalates in spinach was dependent on the introduction of $\mathrm{HU}$ and $\mathrm{KIO}_{3}$ into the nutrient solution only in the hydroponics study (Figure S2A-C and Figure S3A-C). 

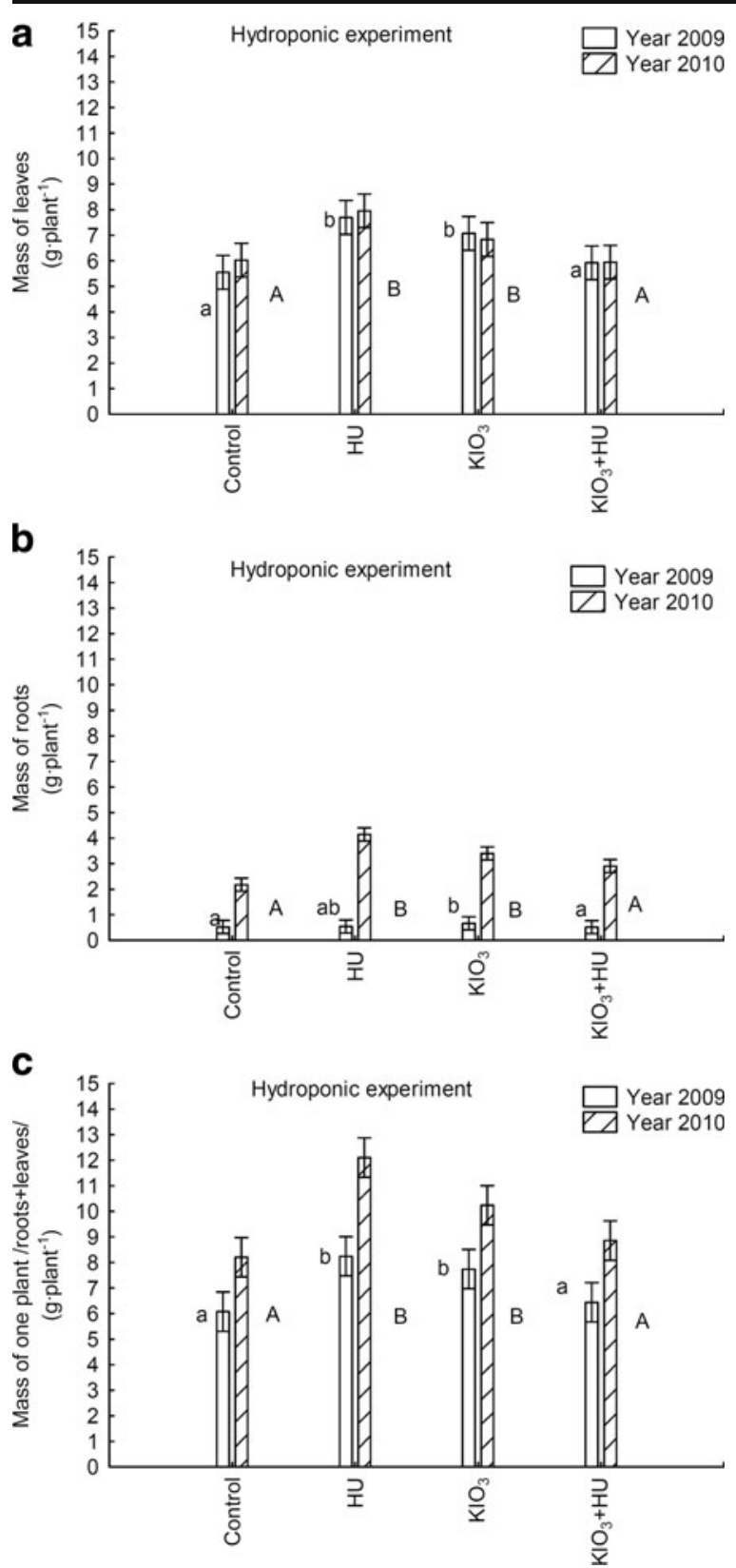

Fig. 2 Fresh mass of leaves (a), roots (b) and whole spinach plants (c) depending on the introduction of Humistar (HU) and $\mathrm{KIO}_{3}$ into the nutrient solution in the hydroponic experiment (NFT system) in 2009 and $2010(n=4)$. Means followed by the same letters are not significantly different at $P<0.05$ : small letters and capital letters represent, respectively, the results from 2009 to 2010. Bars indicate the standard error

The most significant reduction in the accumulation of $\mathrm{Cd}$ in the spinach by the pre-sowing application of KI and $\mathrm{HU}+\mathrm{KI}$ was observed in pot experiment no. 1 in both years of study (Figure S2A). In pot experiment no. 2 , this effect was observed after the pre-sowing fertilization with $\mathrm{KIO}_{3}$ and to a lesser extent, by the application of $\mathrm{KIO}_{3}$ by fertigation or $\mathrm{HU}$ and $\mathrm{HU}+\mathrm{KIO}_{3}$ before seed sowing (Figure S2D).

In all experiments (pot and hydroponic ones), the application of Humistar alone caused a significant increase in $\mathrm{Pb}$ accumulation, and a concomitant decrease in the $\mathrm{Cd}$ concentration in spinach compared to in the control (Figure S2A, B, D and E, Figure S3A and B). Additionally, plant hydroponic cultivation in nutrient solution containing $\mathrm{KIO}_{3}+\mathrm{HU}$ also reduced the concentration of $\mathrm{Cd}$ in the plants. In pot experiment no. 2, the simultaneous pre-sowing application of $\mathrm{KIO}_{3}$ and $\mathrm{HU}+\mathrm{KIO}_{3}$ decreased the level of $\mathrm{Pb}$ accumulation in spinach (Figure S2E).

In the hydroponic plant cultivation system, an increase in the content of soluble oxalates was observed in all tested combinations compared to the control - to the greatest extent in plants in the nutrient solution containing $\mathrm{KIO}_{3}$ (Figure S2C). The accumulation of soluble oxalates in spinach in pot experiments was not affected by the combinations of iodine and Humistar application (Figure S2C and F).

Chemical properties of soil after spinach cultivation in pots

A statistically significant influence of the treatments on the values of $\mathrm{pH}, \mathrm{EC}$, Eh and the content of $\mathrm{I}, \mathrm{Cd}$ and $\mathrm{Pb}$ in the soil after spinach cultivation was observed in both years of both pot experiments (Table S1), with the exception of the soil $\mathrm{Cd}$ and $\mathrm{Pb}$ concentrations in pot experiment no. 1 in 2009 and 2010. The different effects of the tested compounds on the soil characteristics in both pot experiments in 2009 and 2010 was notable.

In pot experiment no. 1, the highest value of Eh in both years of the study was observed in soil fertilized with $\mathrm{HU}+\mathrm{KI}$. In experiment no. 2, soil $\mathrm{pH}$ values were higher than in the control in both years for all combinations with $\mathrm{HU}$ and $\mathrm{KIO}_{3}$ application, with the exception of pre-sowing soil fertilization with $\mathrm{KIO}_{3}$. (Table $\mathrm{S} 1$ ).

In both pot experiments, a comparable and statistically higher level of iodine was observed following treatment with $\mathrm{KI}$ or $\mathrm{KIO}_{3}$ (irrespective of the method and additional $\mathrm{HU}$ introduction), compared to in the control or following the application of HU alone (Table S1). The application of $\mathrm{HU}+\mathrm{KIO}_{3}$ to soil after seed sowing (pot experiment no. 2) caused a slight 

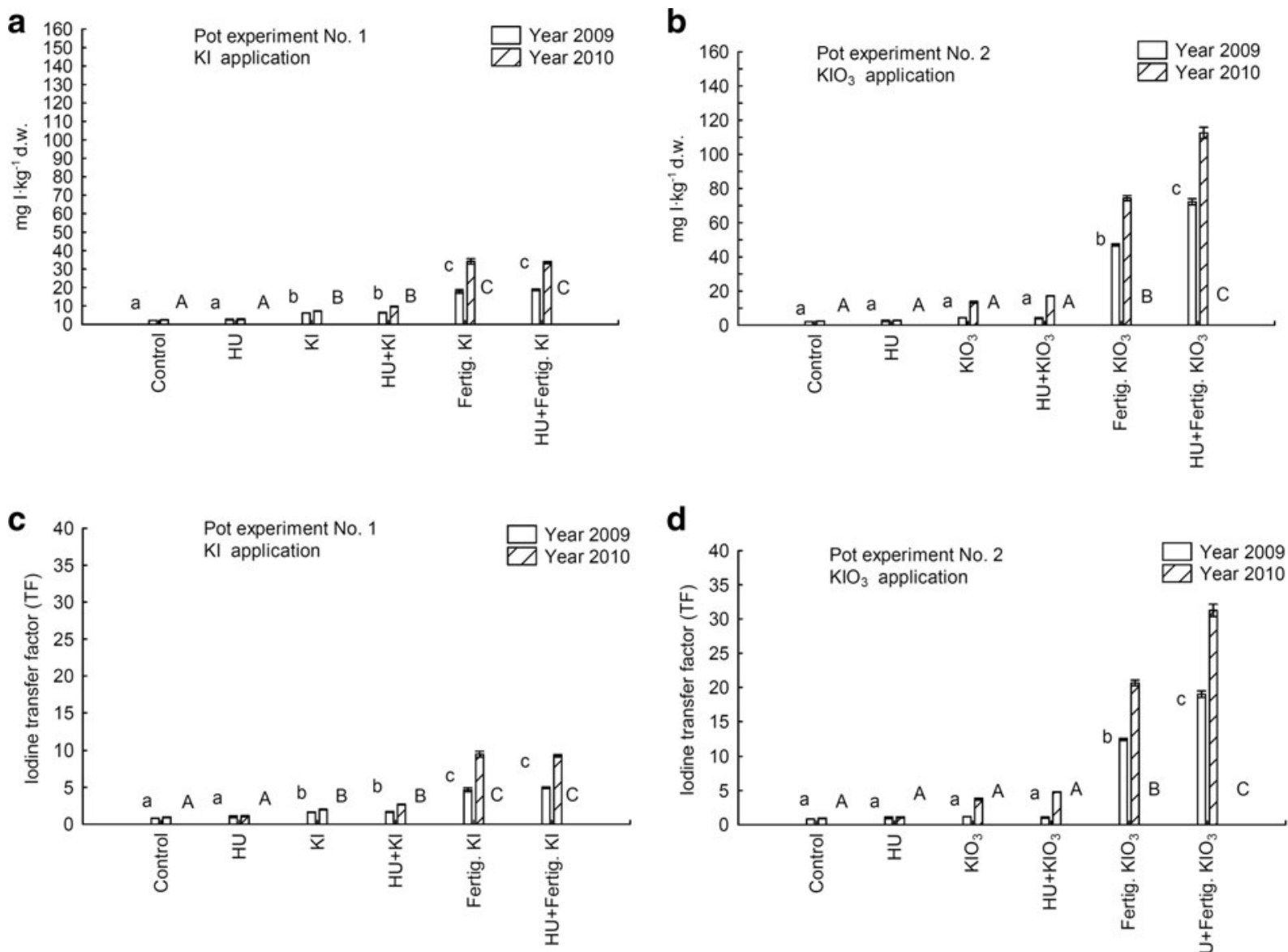

d
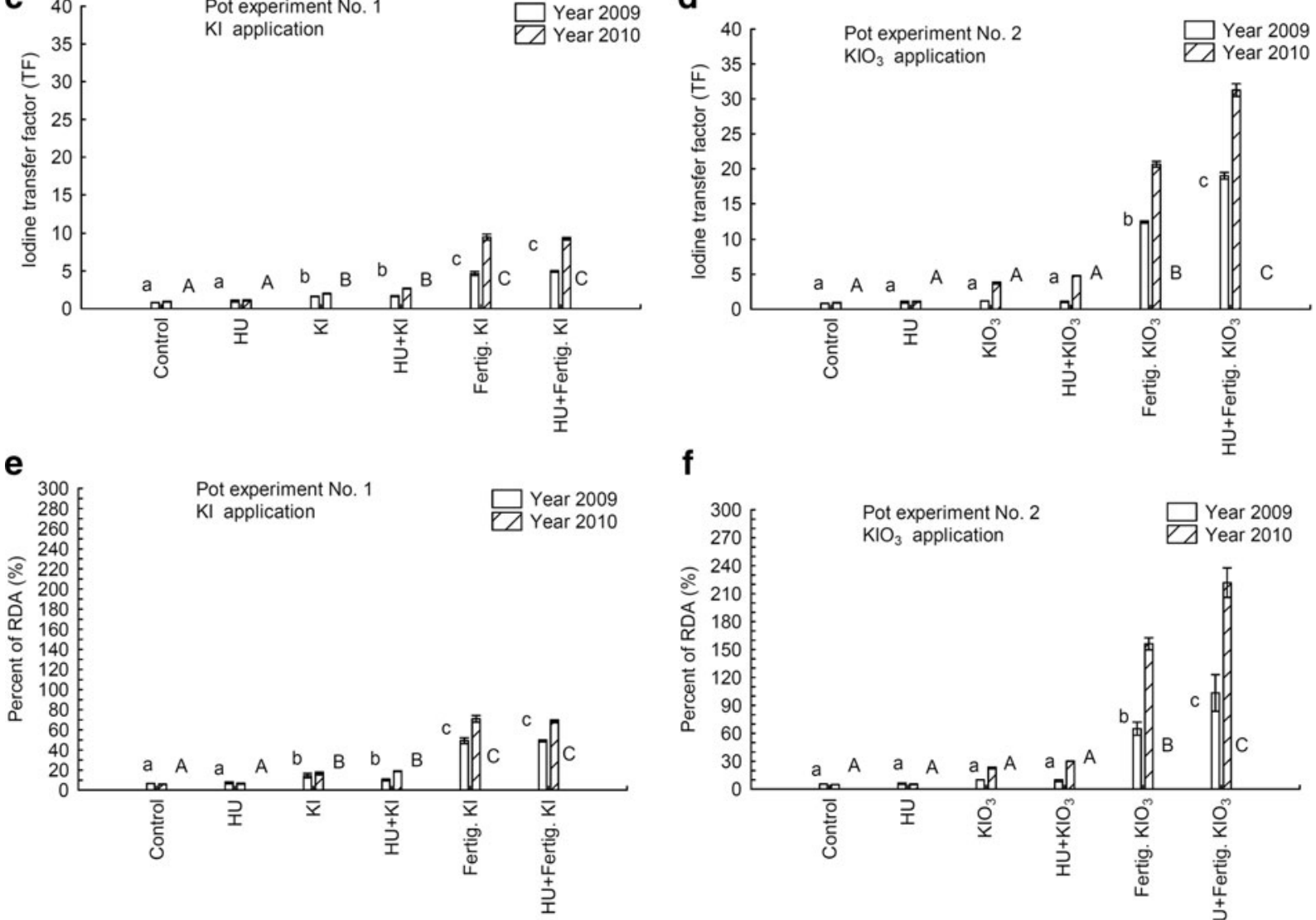

Fig. 3 Iodine content (a and b), transfer factor of iodine (TF) (c and d) to spinach and the percentage RDA of iodine in one serving of spinach leaves (e and $\mathbf{f}$ ), depending on the application of Humistar (HU) and iodine in the form of $\mathrm{KI}(\mathbf{a}, \mathbf{c}, \mathbf{e})$ and $\mathrm{KIO}_{3}$ $(\mathbf{b}, \mathbf{d}, \mathbf{f})$ in pot experiment no. 1 and $2(n=3)$. Means followed by

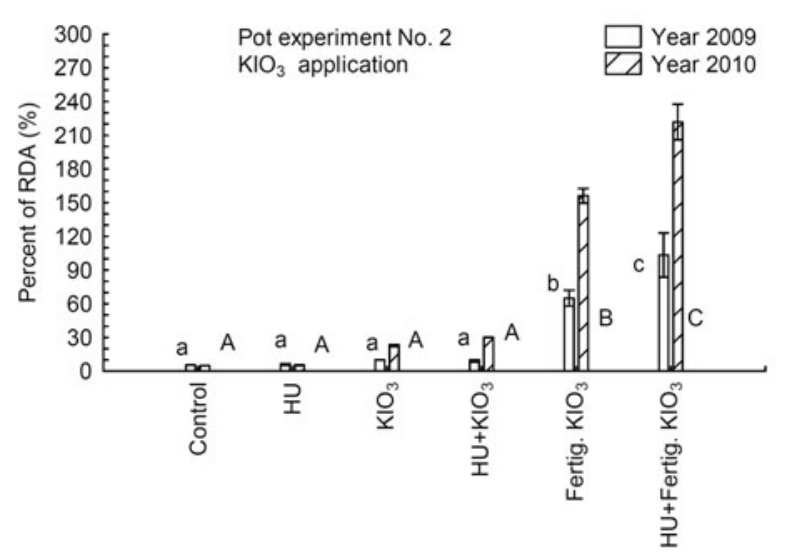

the same letters are not significantly different at $P<0.05$ : small letters and capital letters represent, respectively, the results from 2009 to 2010. Bars indicate the standard error. Percentage of RDA the percentage of the Recommended Daily Allowance in one serving of $50 \mathrm{~g}$ f.w. spinach leaves 

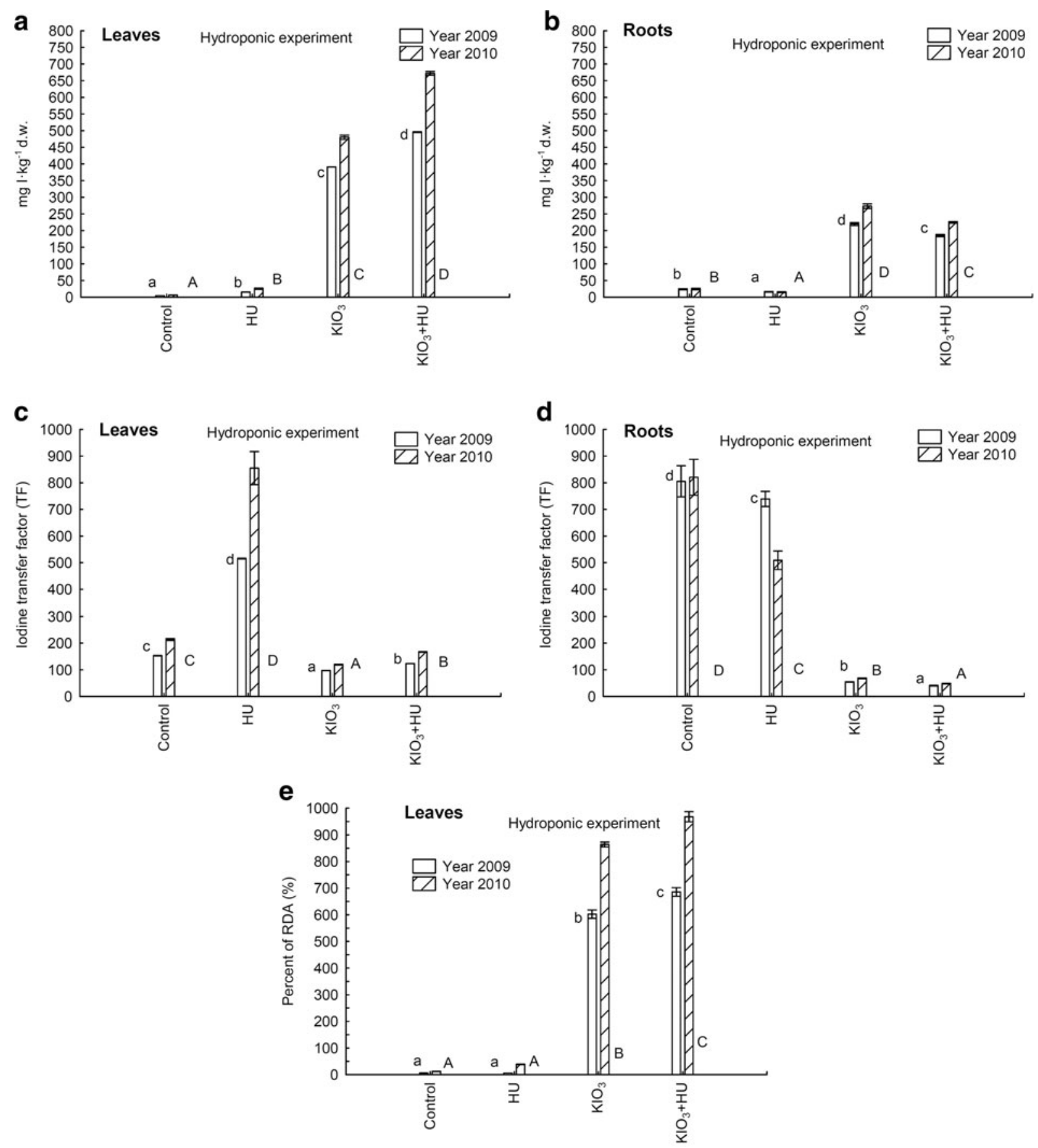

Fig. 4 Iodine content in leaves (a) and roots (b), transfer factor of iodine (TF) to leaves (c) and roots (d) of spinach and percentage of the RDA of iodine in one serving of spinach leaves (e) depending on the introduction of Humistar (HU) and $\mathrm{KIO}_{3}$ into the nutrient solution in the hydroponic experiment (NFT system) in 2009 and $2010(n=4)$. Means followed by the same letters are not significantly different at $P<0.05$ : small letters and capital letters represent, respectively, the results from 2009 to 2010 . Bars indicate standard error. Percentage of $R D A$ the percentage of the Recommended Daily Allowance in one serving of $50 \mathrm{~g}$ f.w. spinach leaves 
increase in the levels of available forms of $\mathrm{Pb}$ and $\mathrm{Cd}$ in the soil.

\section{Discussion}

Spinach biomass

A higher yield was usually obtained in hydroponic cultures than in soil culture. In our opinion, poorer microclimatic conditions in autumn in the plastic tunnel (lower temperatures and a higher relative air humidity) were the main cause of the lower plant weight in the hydroponic treatments than in the pot studies.

The application of $\mathrm{HU}$ and $\mathrm{KIO}_{3}$ into the nutrient solution increased the mass of the spinach plants only in hydroponic cultivation, indicating that when these compounds are applied separately, they might stimulate the development of the root system and leaves. The positive effect of HU on increasing the plant biomass (leaves and roots) in hydroponic culture might be because some molecular components of humic substances regulate plant growth hormones (Pettit 2004). No increase in leaf weight was observed after HU application in the pot experiments. This suggests that the physicochemical properties of the soil reduced the action of HU on the physiological and biochemical processess of the plants.

The reasons for the increase in biomass at low iodine concentrations are unknown (Kabata-Pendias and Mukherjee 2007). A positive effect of low iodine doses (0.01-0.1 p.p.m.) on the increase in plant yield in most cases to the mid-twentieth century has been observed (Borst-Pauwels 1961), which involved plant varieties grown before or at the beginning of the 'green revolution'. Other genetic differences between the old and the new heterotic varieties might exist with respect to the plants' response to iodine. We cultivated a traditional Polish variety of spinach obtained in the 1960 s, which might explain the increased spinach yield in hydroponic culture following the application of $\mathrm{KIO}_{3}$ alone. The effect of iodine on plant biomass productivity depends on the chemical form $\left(\mathrm{I}^{-}\right.$and $\left.\mathrm{IO}_{3}{ }^{-}\right)$and the dosage of the element in soilless culture (Blasco et al. 2008).

The absence of a positive effect of the application of $\mathrm{KIO}_{3}+\mathrm{HU}$ on plant weight in hydroponic culture might be due to a significant increase in the iodine content in the leaves of these plants comparison to those treated with $\mathrm{KIO}_{3}$ alone. The increase was so substantial that the plant weight following the addition of $\mathrm{KIO}_{3}+\mathrm{HU}$ was lower than that following the application of $\mathrm{KIO}_{3}$ or $\mathrm{HU}$ alone. The iodine content in plants treated with $\mathrm{KIO}_{3}+\mathrm{HU}$ was not, however, sufficiently high to reduce the plant weight to a level lower than that in the control. Even small doses of iodine can be harmful to plants (Mackowiak and Grossl 1999; Mackowiak et al. 2005; Hong et al. 2009).

\section{Efficiency of iodine biofortification of spinach}

In studies conducted by Mackowiak et al. (2005), the simultaneous application of HEDTA + HA [chelate $\mathrm{N}$-(2-hydroxyethyl)ethylenedinitrilotriacetic acid + humic acid] to the nutrient solution reduced the negative effect of iodine, applied as $\mathrm{I}^{-}(33.9 \mu \mathrm{M} \mathrm{I})$ and $\mathrm{I}_{2}+\mathrm{I}^{-}$in two doses $(18 \mu \mathrm{M}$ and $30 \mu \mathrm{M})$, on the relative growth rates of rice plants, compared to treatment with HEDTA alone. Additionally, a decrease in the iodine content of rice shoots was observed only for HEDTA + HA treatment when applied with a lower $\mathrm{I}_{2}+\mathrm{I}^{-}$dose in the nutrient solution. The application of HEDTA + HA also reduced the accumulation of iodine in the roots of rice cultivated in the presence of both levels of $\mathrm{I}_{2}+\mathrm{I}^{-}$in the nutrient solution.

In pot experiment no. 1, no significant effect of the humic and fulvic acids present in Humistar was observed on iodine accumulation or on the values of $\mathrm{TF}$ and RDA in the upper parts of spinach cultivated on soil treated with KI applied before seed sowing or with fertigation. However, in pot experiment No. 2, a positive effect of HU was observed on root-to-leaf transfer, and on the accumulation of iodine (or RDA values) when $\mathrm{KIO}_{3}$ was applied with fertigation but not by pre-sowing fertilization. Similar results were obtained in the hydroponic experiment, which showed that the iodine content in the roots from the treatments with $\mathrm{HU}$ or $\mathrm{KIO}_{3}+\mathrm{HU}$ was lower than in the control or $\mathrm{KIO}_{3}$ treatments, respectively. The application of HU to the nutrient solution also significantly increased iodine accumulation and TF in spinach leaves. The mechanism for the effect of HU on iodine transfer from roots to leaves, as well as why the efficiency of plant fertigation was limited only to the $\mathrm{IO}_{3}{ }^{-}$form of iodine, is unclear.

Yamada et al. (1996) demonstrated that following the introduction of mineral iodine into the soil, undetermined organic iodine compounds formed between 5.6 and $20.3 \%$ of the total iodine content (the remaining being iodine in the form of $\mathrm{I}^{-}$and $\mathrm{IO}_{3}{ }^{-}$) in water-soluble iodine in soil extracts. The authors also demonstrated 
that soil extraction with water makes it possible to determine exogenous (synthetic) organo-iodine compounds introduced into the soil with a very good recovery, i.e., L-thyroxine 5-iodocytosine, 7-Iodo-8hydroxyquinoline-5-sulfonic acid and $o$-Iodoenzoic acid. Iodoacetic anions $\left(\mathrm{CH}_{2} \mathrm{ICOOH}^{-}\right)$can be taken up by plants in amounts comparable to or greater than those of $\mathrm{I}^{-}$and $\mathrm{IO}_{3}{ }^{-}$(Umaly and Poel 1971; Weng et al. 2008). However, no clear evidence shows that plants uptake organo-iodine compounds other than the $\mathrm{CH}_{2} \mathrm{ICOOH}^{-}$ ion. We demonstrated in another study (patent application by Sady et al. 2014) that lettuce plants in hydroponic culture can absorb 5-iodosalicylic acid, 3,5diiodosalicylic acid, 2-iodobenzoic acid and 2,3,5triiodobenzoic acid from the nutrient solution and we confirmed the presence of these compounds in leaves.

Soil contains various organic acids, including salicylic acid (Hue et al. 1986), which (with its derivatives) is included within the SOM. In experiment no. 2 and in hydroponic cultivation, iodate ions might have interacted with the humic or fulvic acids present in Humistar. Ions of $\mathrm{IO}_{3}{ }^{-}$introduced into the soil through fertigation in low doses might have been chemically reduced to $\mathrm{I}_{2}$ (or $\mathrm{I}$ ) by soil microorganisms and soil organic matter (Yamaguchi et al 2005) or onto the surface of roots (Kato et al. 2013). Because molecular iodine $\left(\mathrm{I}_{2}\right)$ is more reactive, it probably binds to the aromatic rings of such compounds. The resultant complexes (I+ humic acids, I+ fulvic acids or I+ soil organic matter) might have been directly taken up by roots and transported and accumulated more easily than $\mathrm{I}^{-}$or $\mathrm{IO}_{3}{ }^{-}$ in stems and leaves, leading to the increased adsorption and movement of iodine (indicated by TF values) in the hydroponic experiment. We cannot, however, provide clear evidence that organo-iodine compounds (e.g., iodosalicylates, iodobenzoates or their derivatives) formed in the soil or the nutrient solution, following the application of $\mathrm{HU}$ and fertigation with $\mathrm{KIO}_{3}$.

The lack of influence of pre-sowing $\mathrm{HU}+\mathrm{KI}$ fertigation (pot experiment no. 1) on iodine absorption might be affected by an adverse mechanism of iodide transformation in soil. The oxidation of $\mathrm{I}^{-}$ions into $\mathrm{I}_{2}$ (which can then potentially react with humic and fulvic acids present in $\mathrm{HU}$ ) occurs efficiently at an acidic $\mathrm{pH}$ and $\mathrm{Eh}$ values between +600 and $+900 \mathrm{mV}$, in the presence of iron and manganese cations (Fuge and Johnson 1986; Johnson 2003; Ashworth et al. 2003; Fuge 2013). Thus, in the experimental conditions (with Eh values after the spinach harvest between $+318.1 \mathrm{mV}$ and $+360.0 \mathrm{mV}$ ), $\mathrm{I}^{-}$oxidation was theoretically was unlikely. On the other hand, in aerobic conditions at Eh values of about $+300 \mathrm{mV}$, the process of $\mathrm{IO}_{3}{ }^{-}$reduction to $\mathrm{I}_{2}$ occurs relatively easily in the soil or the rhizosphere (Fuge and Johnson 1986).

The absence of an effect of the simultaneous presowing application of $\mathrm{HU}$ and iodine (HU $+\mathrm{KI}$ and $\mathrm{HU}+\mathrm{KIO}_{3}$ compared to $\mathrm{KI}$ or $\mathrm{KIO}_{3}$ alone, respectively) on iodine uptake by spinach plants (or TF and RDA values) might be due to the strong sorption of iodine ions in the soil. Iodine desorption is very slow (Dai et al 2004), which explains why soil fertigation with $\mathrm{KIO}_{3}$ and $\mathrm{KI}$ in both pot experiments was more effective with respect to the iodine biofortification of spinach (and TF or RDA factor) than its application before seed sowing.

In the hydroponic experiment, a higher TF for iodine was obtained in the control vs. $\mathrm{KIO}_{3}$ and $\mathrm{HU}+\mathrm{KIO}_{3}$ treatments in leaves, and vs. $\mathrm{HU}, \mathrm{KIO}_{3}$ and $\mathrm{HU}+\mathrm{KIO}_{3}$ treatments in roots. This might have been due to the more rapid uptake of iodine from the nutrient solution by the control plants than those cultivated in soil, where the availability of iodine to plants was limited by sorption. The leaf iodine content was 0.92 and $1.07 \mathrm{mg}$ $\mathrm{I} \cdot \mathrm{kg}^{-1}$ d.w. in 2009 and 2010, respectively in plants in the control nutrient solution $\left(30 \mu \mathrm{g} \mathrm{I} \cdot \mathrm{dm}^{-3}\right.$ in the nutrient solution). Notably not all of the iodine was absorbed from the nutrient solution in the plots treated with $\mathrm{KIO}_{3}$ and $\mathrm{KIO}_{3}+\mathrm{HU}$. After the end of spinach cultivation, the nutrient solution contained 2.71 and $2.76 \mathrm{mg} \mathrm{I} \cdot \mathrm{dm}^{-3}$ $\mathrm{KIO}_{3}$ and $\mathrm{KIO}_{3}+\mathrm{HU}$, respectively in 2009, and 2.95 and $2.63 \mathrm{mg} \mathrm{I} \cdot \mathrm{dm}^{-3}$, respectively, in 2010 . Therefore, from the initial concentration of $4 \mathrm{mg} \mathrm{I} \cdot \mathrm{dm}^{-3}$ in the nutrient solution, the plants absorbed 32.3 and $31.0 \%$ in 2009 and 26.3 and $34.3 \%$ in 2010 , respectively in these plots. In the control treatment, however, the plants absorbed practically all of the iodine from the nutrient solution. The relatively high TF values for the leaves and roots of the control plants in the hydroponic treatment, therefore, are a direct result of the algorithm used to calculate the transfer factor. As a consequence of the increased iodine uptake in the $\mathrm{KIO}_{3}$ and $\mathrm{KIO}_{3}+\mathrm{HU}$ plots in the hydroponic treatment, or with the application of $\mathrm{HU}$ together with $\mathrm{KI}$ or $\mathrm{KIO}_{3}$ fertigation in the pot experiments, the degree of iodine methylation might have increased. This is viewed as a mechanism of plant detoxification for this element (Rhew et al. 2003). Methylation might have caused some iodine loss from the leaves, and thus, have affected the calculated TF. 
An increase in iodine accumulation and TF or RDA values in spinach leaves after fertigation (with $\mathrm{KI}$ and $\mathrm{KIO}_{3}$ ) in both pot experiments might be because this method ensures a better availability of this element for plants. With the traditional pre-sowing application, iodine moves very slowly within soil via leaching water (Weng et al. 2009), which limits its availability and uptake by roots. Furthermore, microorganisms and/or their products (e.g., enzymes) might additionally participate in the process of iodine accumulation in soil (Muramatsu et al. 2004).

It is generally acknowledged that plants grown in the presence of iodides $(\Gamma)$ take up more iodine than after the introduction of iodates $\left(\mathrm{IO}_{3}{ }^{-}\right)$into soil (BorstPauwels 1961; Smith et al. 1999; Mackowiak and Grossl 1999; Gonda et al. 2007; Zhu et al. 2003). A comparison of the results of both pot experiments indicates the opposite relationship concerning the preference by spinach plants towards the uptake of a particular form of iodine. The potential reason for the better uptake of $\mathrm{IO}_{3}^{-}$over $\mathrm{I}^{-}$(a higher TF value for $\mathrm{IO}_{3}{ }^{-}$than $\mathrm{I}^{-}$, especially when applied with fertigation) might relate to the previously described processes of iodine transformations in the soil during the spinach cultivation. Furthermore, Dai et al. (2006) showed that roots and leaves of spinach fertilized with iodates accumulated more iodine than those treated with iodides. Therefore, differences in iodine uptake by plants (and TF or RDA values), when applied in particular forms, reported by various studies might result from diverse physicochemical properties of soil as well as from different iodine doses, methods of application and various processes of its transformation in soils. Additionally, species preferences might exist, in the uptake of both forms. We assume that in our research, iodine might have undergone processes of sorption with SOM or the mineral soil fraction upon introduction into the soil, e.g., with $\mathrm{Al}$ hydroxide or other compounds. Aluminium is responsible for soil acidification, therefore, the binding of iodine with $\mathrm{Al}$ hydroxides (or $\mathrm{Fe}$ hydroxide, $\mathrm{Cu} / \mathrm{Al}, \mathrm{Cu} / \mathrm{Cr}$ hydroxide, $\mathrm{Cu}(\mathrm{I})$-sulphides or $\mathrm{Cu}(\mathrm{I})-\mathrm{Fe}(\mathrm{III})$-sulphides), as well as the presence of iodine alone in the soil, might have influenced the changes in $\mathrm{pH}, \mathrm{Eh}, \mathrm{EC}$, and the content of the forms of $\mathrm{Cd}$ and $\mathrm{Pb}$ available to the plants.

Following the introduction of $\mathrm{HU}$ alone before seed sowing in both pot experiments, a significantly higher level of iodine was observed in the soil (extracted with $0.03 \mathrm{M}$ acetic acid) than before spinach cultivation. This might indicate that the HU present in the soil triggered the transformation of absorbed iodine compounds into products that were more soluble in $0.03 \mathrm{M}$ acetic acid. Notably, in the iodine application treatments (pre-sowing or by fertigation), a slightly higher soil level of iodine was observed after spinach cultivation, which should have resulted from the sum of the initial content and the iodine dose used. This might suggest that the introduction of iodine into soil with growing plants promotes the formation of iodine compounds that are soluble in $0.03 \mathrm{M}$ acetic acid. Yuita et al. (2006) reported an increase in the iodine content in soil during a spring season that was followed by an increase of air temperature and soil humidity after winter.

Concerning consumer requirements, soil fertigation with $\mathrm{KI}$ and $\mathrm{KIO}_{3}$ in the pot experiments caused a substantial increase in RDA values for spinach, compared to those after the one-time pre-sowing application of these compounds (irrespective of HU application). The resulting level of iodine biofortification of spinach after KI fertigation with and without HU (pot experiment no. 1) was sufficient for consumers, i.e., RDA values within the range from 50 to $70 \%$. With fertigation with $\mathrm{KIO}_{3}$ in a pot experiment, especially when applied with $\mathrm{HU}$, the iodine concentration in spinach could be increased to a level that exceeds consumer requirements, i.e., RDA values from 65 to $220 \%$. In hydroponic cultivation, the RDA value in the combination with $\mathrm{KIO}_{3}$ fertigation (alone or together with $\mathrm{HU}$ ) remained within the range of $600-1,000 \%$. Therefore, to develop agro-technical rules for the iodine biofortification of spinach using $\mathrm{KIO}_{3}$ fertigation, lower iodine doses (than those applied in our studies) can be used to obtain sufficient and safe RDA values. Spinach can be consumed fresh or after thermal processing. As shown by the research of Cerretani et al. (2014), thermal processing leads to iodine loss in vegetables, although they are still an excellent source of iodine in the diet.

Accumulation of $\mathrm{Cd}, \mathrm{Pb}$ and oxalates in spinach

A significant increase in $\mathrm{Cd}$ accumulation was observed in leaves of spinach cultivated in the hydroponic experiment due to the introduction of $\mathrm{KIO}_{3}$ to the nutrient solution. Currently, no known mechanisms can directly explain the difference in $\mathrm{HU}$ interaction with $\mathrm{KI}$ and $\mathrm{KIO}_{3}$ (when applied either prior to sowing or with fertigation) with respect to $\mathrm{Cd}$ and $\mathrm{Pb}$ accumulation in spinach plants. 
Spinach is a crop species characterised by a high content of oxalates (Jaworska and Kmiecik 1999). An increased accumulation of organic acids in plants is one indicator of unfavourable metabolic processes in plant cells, which, for example, are triggered by biotic and abiotic stress factors. Calcium oxalate crystal formation in plants appears to play a central role in a variety of other important functions, including tissue calcium regulation, protection from herbivory and metal detoxification (Nakata 2003). In our studies, an increase in the soluble oxalate concentration only in the hydroponic experiment was related to the increased content of $\mathrm{Cd}$ in plants treated with $\mathrm{KIO}_{3}$. The simultaneous introduction of $\mathrm{KIO}_{3}+\mathrm{HU}$ into the nutrient solution (compared to $\mathrm{KIO}_{3}$ alone) resulted in a decrease in $\mathrm{Cd}$ and oxalate accumulation in the plants. Based on the results of the pot experiments, the increased content of oxalates in spinach leaves cannot be linked to the process of iodine biofortification.

In summary, fertigation with $\mathrm{KI}$ and $\mathrm{KIO}_{3}$ during the cultivation leads to a significantly stronger effect of iodine biofortification (and TF or RDA) of spinach plants compared to the pre-sowing introduction of this element into the soil. Fertigation with iodine compounds at even lower doses than those applied in the pot experiments $(0.0004 \%$ iodine solution) can reduce the costs of iodine fortification of plants. This is further substantiated by the values of RDA, which in pot experiment no. 1 were close to, or exceeded, the optimum daily intake of iodine contained by a serving of $50 \mathrm{~g}$ spinach fresh leaves. We assume that iodine accumulation in plants to a level comparable to that observed after presowing fertilization with $\mathrm{KI}$ or $\mathrm{KIO}_{3}$ can be obtained by using lower doses of iodine. An additional advantage of fertigation as a method of iodine introduction into soil is that it does not increase the accumulation of $\mathrm{Cd}$ and $\mathrm{Pb}$ in spinach.

The combination of $\mathrm{HU}$ application with $\mathrm{KIO}_{3}$ fertigation (applied in pot experiment no. 2 and the hydroponic cultivation) improved the transfer of iodine from roots to leaves, resulting in the increased accumulation of iodine in the leaves. In plant culture using a NFT system, a positive effect of $\mathrm{HU}+\mathrm{KIO}_{3}$ was observed with respect to the limited accumulation of $\mathrm{Cd}$ and oxalates compared to the application of $\mathrm{KIO}_{3}$ alone. Notably, the content of $\mathrm{Cd}$ in spinach grown in the presence of KI and HU was significantly lower than that in the control. We can also conclude from the results of the pot experiments that $\mathrm{IO}_{3}{ }^{-}$ions (or products of its transformation in soil) are more easily taken up by spinach plants than $\mathrm{I}^{-}$ions. However, despite the significant increase in the iodine content (and TF of RDA factors), no significant influence on the biomass (yield) was observed.

The literature on iodine biogeochemistry does not provide sufficient information with which to unequivocally interpret all of the results in this study. Therefore, it is necessary to confirm some of our findings by further experiments concerning the mechanism of the interaction between various chemical forms of iodine with humic acids in the soil environment and plants, as well as the accumulation of hazardous chemicals $(\mathrm{Cd}, \mathrm{Pb}$, oxalates) in crops.

Acknowledgments This work was financed by research grants from the Ministry of Science and Higher Education of the Republic of Poland. The results of the study were reported to the Polish Patent Office - Patent application No. P. 410807.

Open Access This article is distributed under the terms of the Creative Commons Attribution 4.0 International License (http:// creativecommons.org/licenses/by/4.0/), which permits unrestricted use, distribution, and reproduction in any medium, provided you give appropriate credit to the original author(s) and the source, provide a link to the Creative Commons license, and indicate if changes were made.

\section{References}

Andersson M, de Benoist B, Darnton-Hill I, Delange F (2007) Iodine deficiency in Europe: a continuing public health problem. World Health Organization, Geneva

Ashworth DJ, Shaw G, Butler AP, Ciciani L (2003) Soil transport and plant uptake of radio-iodine from near-surface groundwater. J Environ Radioact 70:99-114

Blasco B, Rios JJ, Cervilla LM, Sanchez-Rodriguez E, Ruiz JM, Romero L (2008) Iodine biofortification and antioxidant capacity of lettuce: potential benefits for cultivation and human health. Ann Appl Biol 152:289-299

Borst-Pauwels GWFH (1961) Iodine as a micronutrient for plants. Plant Soil 14(4):377-392

Cerretani L, Comandini P, Fumanelli D, Scazzina F, Chiavaro E (2014) Evaluation of iodine content and stability in recipes prepared with biofortified potatoes. Int J Food Sci Nutr 65(7): 797-802

Charlton KE, Phil M, Gemming L, Yeatman H, Ma G (2010) Suboptimal iodine status of Australian pregnant women reflects poor knowledge and practices related to iodine nutrition. Nutrition 26:963-968

Dai JL, Zhang M, Zhu YG (2004) Adsorption and desorption of iodine by various Chinese soils. I. Iodate. Environ Int 30: 525-530

Dai JL, Zhu YG, Huang YZ, Zhang M, Song JL (2006) Availability of iodide and iodate to spinach (Spinacia 
oleracea $L$.) in relation to total iodine in soil solution. Plant Soil 286:301-308

Delange F (1998) Risks and benefits of iodine supplementation. Lancet 351:923-924

Fuge R (2013) Soils and iodine deficiency. In: Selinus O, Alloway B, Centeno JA, Finkelman RB, Fuge R, Lindh U, Smedley P (eds) Essentials of medical geology: revised edition. Elsevier Academic Press, London, pp 417-432

Fuge R, Johnson CC (1986) The geochemistry of iodine - a review. Environ Geochem Health 8(2):31-54

Gonda K, Yamaguchi H, Maruo T, Shinohara Y (2007) Effects of iodine on growth and iodine absorption of hydroponically grown tomato and spinach. Hortic Res Jpn 6(2):223-227

Gorlach E, Curyło T, Gambuś F, Grzywnowicz I, Jasiewicz C, Kopeć M, Mazur B, Olkuśnik S, Rogóż A, WiśniowskaKielian B (1999) Guide for agricultural chemistry. Agricultural University in Cracow. (In Polish)

Guyot H, de Oliveira LA, Ramery E, Beckers JF, Rollin F (2011) Effect of a combined iodine and selenium supplementation on I and Se status of cows and their calves. J Trace Elem Med Biol 25:118-124

Hakimi SS (1996) Improved iodine-125 removal in anionic form of iodate by column method using laterite soil. J Radioanal Nucl Chem 214(2):117-131

Hong CL, Weng HZ, Yan AL, Islam AU (2009) The fate of exogenous iodine in pot soil cultivated with vegetables. Environ Geochem Health 31(1):99-108

Hue NV, Craddock GR, Adams F (1986) Effect of organic acids on aluminum toxicity in subsoils. Soil Sci Soc Am J 50(1):28-34

Jaworska G, Kmiecik W (1999) Content of selected mineral compounds, nitrates III and V, and oxalates in spinach (Spinacia oleracea L.) and New Zealand spinach (Tetragonia expansa Murr.) from spring and autumn growing seasons. EJPAU 2 (2). http://www.ejpau.media.pl/volume2/ issue2/food/art-03.html. Accessed 27 May 2014

Johanson KJ (2000) Iodine in soil. Technical Report. TR-00-21. Svensk Kärnbränslehantering AB. http://193.235.25.3/ upload/publications/pdf/TR-00-21webb.pdf. Accessed 18 Aug 2012

Johnson CC (2003) The geochemistry of iodine and its application to environmental strategies for reducing the risks from iodine deficiency disorders (IDD). British Geol Survey Comm Report CR/03/057N

Kabata-Pendias A, Mukherjee AB (2007) Trace elements from soil to human. Springer, Berlin

Kashparov V, Colle C, Zvarich S, Yoschenko V, Levchuk S, Lundin S (2005) Soil-to-plant halogens transfer studiem 1. Root uptake of radioiodine by plants. J Environ Radioact 79: 187-204

Kato S, Wachi T, Yoshihira K, Nakagawa T, Ishikawa A, Takagi D, Tezuka A, Yoshida H, Yoshida S, Sekimoto H, Takahashi M (2013) Rice (Oryza sativa L.) roots have iodate reduction activity in response to iodine. Front. Plant Sci 4:227. doi:10. 3389/fpls.2013.00227

Lefèvre G, Bessière J, Ehrhardt JJ, Walcarius A (2003) Immobilization of iodide on copper(I) sulfide minerals. J Environ Radioact 70:73-83

Mackowiak CL, Grossl PR (1999) Iodate and iodine effects on iodine uptake and partitioning in rice (Oryza sativa L.) grown in solution culture. Plant Soil 212:135-143
Mackowiak CL, Grossl PR, Cook KL (2005) Iodine toxicity in a plant-solution system with and without humic acid. Plant Soil 269:141-150

Melse-Boonstra A, Jaiswal N (2010) Iodine deficiency in pregnancy, infancy and childhood and its consequences for brain development. Best Pract Res Clin Endocrinol Metab 24:29-38

Muramatsu Y, Uchida S, Sriyotha P, Sriyotha K (1990) Some considerations on the sorption and desorption phenomena of iodide and iodate on soil. Water Air Soil Pollut 49:125138

Muramatsu Y, Yoshida S, Uchida S (1996) Iodine desorption from rice paddy soil. Water Air Soil Pollut 86:359-371

Muramatsu Y, Yoshida S, Fehn U, Amachi S, Ohmomo Y (2004) Studies with natural and anthropogenic iodine isotopes: iodine distribution and cycling in the global environment. $\mathrm{J}$ Environ Radioact 74:221-232

Nakata PA (2003) Advances in our understanding of calcium oxalate crystal formation and function in plants. Plant Sci 164(6):901-909

Nowosielski O (1988) The rules in development of fertilizing strategies in horticulture. PWRiL Publisher, Warsaw (In Polish)

Pasławski P, Migaszewski ZM (2006) The quality of element determinations in plant materials by instrumental methods. Pol J Environ Stud 15(2a):154-164

Pettit RE (2004) Organic matter, humus, humate, humic acid, fulvic acid and humin: Their importance in soil fertility and plant health. CTI Research

Pless JD, Chwirka JB, Krumhansl JL (2007) Iodine sequestration using delafossites and layered hydroxides. Environ Chem Lett 5:85-89

PN-EN 15111 (2008) Foodstuffs - Determination of trace elements - Determination of iodine by ICP-MS (inductively coupled plasma mass spectrometry). Polish Committee of Standardization, Warsaw. (In Polish)

Rhew RC, Østergaard L, Saltzman ES, Yanofsky MF (2003) Genetic control of methyl halide production in Arabidopsis. Curr Biol 13:1809-1813. doi:10.1016/j.cub.2003.09.055

Sady W, Smoleń S, Ledwożyw-Smoleń S (2014) Methods of biofortification of vegetables with iodine in hydroponic cultures. Patent application No. P.410806 - Polish Patent Office 30 XII 2014

Schlegel ML, Reiller P, Mercier-Bion F, Barré N, Moulin V (2006) Molecular environment of iodine in naturally iodinated humic substances: insight from X-ray absorption spectroscopy. Geochim Cosmochim Acta 70:5536-5551

Smith LC, Morton JD, Catto WD (1999) The effects of fertiliser iodine application on herbage iodine concentration and animal blood levels. N Z J Agric Res 42:433-440

Tyler LD, McBride MB (1982) Influence of $\mathrm{Ca}, \mathrm{pH}$ and humic acid on Cd uptake. Plant Soil 64(2):259-262

Umaly RC, Poel LW (1971) Effects of iodine in various formulations on the growth of barley and pea plants in nutrient solution culture. Ann Bot 35:127-131

Vinogradov AP, Lapp MA (1977) Use of iodine haloes to search for concealed mineralization. Vestn-Leningradski Univ Ser Geol Geog 24:70-76

Voogt W, Holwerda HT, Khodabaks R (2010) Biofortification of lettuce (Lactuca sativa L.) with iodine: the effect of iodine form and concentration in the nutrient solution on growth, 
development and iodine uptake of lettuce grown in water culture. J Sci Food Agric 90:906-913

Walker SP, Wachs TD, Gardner JM, Lozoff B, Wasserman GA, Pollitt E, Carter JA (2007) Child development: risk factors for adverse outcomes in developing countries. Lancet 369: 145-157

Weng HX, Yan AL, Hong CL, Xie L, Qin YC, Cheng CQ (2008) Uptake of different species of iodine by water spinach and its effect to growth. Biol Trace Elem Res 124:184-194

Weng HX, Yan AL, Hong CL, Qin YC, Pan L, Xie LL (2009) Biogeochemical transfer and dynamics of iodine in a soilplant system. Environ Geochem Health 31(3):401-411

White PJ, Broadley MR (2009) Biofortification of crops with seven mineral elements often lacking in human diets - iron, zinc, copper, calcium, magnesium, selenium and iodine. New Phytol 182(1):49-84

Wierzbicka E (2004) The assessment of the content of soluble oxalates in selected stimulants. In: Brzozowska A (ed) Food toxicology. Lab manual. Warsaw University of Life Science Press, Warsaw (In Polish)

Winger RJ, König J, House DA (2008) Technological issues associated with iodine fortification of foods. Trends Food Sci Technol 19:94-101

Yamada H, Sugahara M, Kosaka H, Katayama A, Takahashi K, Yonebayashi K (1996) Determination of total and water soluble iodine in soil by high performance liquid chromatography. Soil Sci Plant Nutr 42(2):367-374

Yamaguchi N, Nakano M, Tanida H (2005) Transformation of iodine species in soil under upland field and submerged paddy field conditions. SPring-8 Res Front 2005. http:// www.spring8.or.jp/pdf/en/res_fro/05/112-113.pdf Accessed: 24 June 2012

Yamaguchi N, Nakano M, Tanida H, Fujiwara H, Kihou N (2006) Redox reaction of iodine in paddy soil investigated by field observation and the I K-Edge XANES fingerprinting method. J Environ Radioact 86:212226

Yoshida S, Muramatsu Y, Uchida S (1992) Studies on the sorption of $\mathrm{I}^{-}$(iodide) and. $\mathrm{IO}_{3}{ }^{-}$(iodate) onto andosols. Water Air Soil Pollut 63:321-329

Yuita K, Kihou N, Ichihashi H, Yabusaki S, Fujiwara H, Kurishima K, Noda T (2006) Behavior of iodine in a forest plot, an upland field and a paddy field in the upland area of Tsukuba, Japan: Seasonal variations in iodine concentration in precipitation and soil water and estimation of the annual iodine accumulative amount in soil horizons. Soil Sci Plant Nutr 52(1):122-132

Zhu YG, Huang YZ, Hu Y, Liu YX (2003) Iodine uptake by spinach (Spinacia oleracea L.) plants grown in solution culture: effects of iodine species and solution concentrations. Environ Int 29:33-37 